\title{
Preparation of $\mathbf{2} \mathrm{nm}$ gold nanoparticles for in vitro and in vivo applications
}

\author{
Daniel F. Moyano ${ }^{\mathrm{a}}$, Bradley Duncan ${ }^{\mathrm{a}}$, and Vincent M. Rotello ${ }^{\star}, \mathrm{a}$ \\ a Department of Chemistry, University of Massachusetts, 710 North Pleasant Street, Amherst, \\ Massachusetts 01003, USA
}

\section{Summary}

Gold nanoparticles have been a versatile tool in recent years for the exploration of biological systems. However, challenges with purification and adequate surface coverage limit the biocompatibility of gold nanoparticles. Here, we describe a detailed procedure for the synthesis, purification, and functionalization of biologically compatible gold nanoparticles for in vitro and in vivo studies.

\section{Keywords}

Gold nanoparticle; biocompatibility; purification

\section{Introduction}

Gold nanoparticle (AuNP) properties and applications continue to be the focus of variety of fields since their discovery in 1857 by Michael Faraday (1). Among these areas, avid research has been pointed towards the creation of biocompatible nanoparticles (2). The precise control introduced by the two-phase Brust-Schiffrin method $(3,4)$ allowed more systematic studies of nanoparticle properties to be performed. However, the use of tetra-noctylammonium bromide as the phase transfer catalyst limits biological applications due to the difficultly in separating this high cytotoxic chemical from the nanoparticles $(5,6)$. Additionally, the functionality of nanoparticle surfaces has been a prominent concern due to the direct correlation of cytotoxicity with the functionality of the surface monolayer (7). To further improve nanoparticle utility, a fine balance between hydrophobic functionalization near the metallic core to confer monolayer stability (8) and non-fouling character provided by poly(ethylene glycol) moieties must be achieved (9). An excellent ligand base for biological applications is 23-mercapto-3,6,9,12-tetraoxatricosan-1-ol (Figure 1) as its components confer the desired stability and non-fouling properties (10). This structure can be easily modified to provide selective binding making these nanoparticles a promising platform for systematic biological studies (11). Employing these concepts, this protocol elaborates on the synthesis, purification and functionalization of gold nanoparticles with the biocompatibility required for in vivo and in vitro studies.

\footnotetext{
'Corresponding author. rotello@ chem.umass.edu.
} 


\section{Materials}

1. Hydrogen tetrachloroaurate (III) hydrate.

2. Tetra-n-octylammonium bromide (TOAB).

3. 1-Pentanethiol.

4. Sodium borohydride.

5. 23-mercapto-3,6,9,12-tetraoxatricosan-1-ol, synthetized according to the reported procedure (12).

6. 200 proof ethanol, acetone, hexanes and acetonitrile.

7. 10,000 MWCO snakeskin pleated dialysis tubing membrane.

8. $3.0 \mathrm{~cm}$ Grade 1 filter paper circles.

\section{Methods}

All procedures are done at room temperature unless otherwise specified.

\subsection{Synthesis of gold nanoparticles (from the Brust-Schiffrin method) (3)}

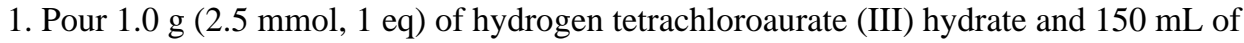
Type I ultrapure water into a $1000 \mathrm{~mL}$ round bottom flask. Stir slowly for 5 minutes using a 2 inch egg-shaped magnetic stir bar until complete dissolution. Solution should be clear yellow (see Note 1).

2. Premix $2.1 \mathrm{~g}$ ( $3.8 \mathrm{mmol}, 1.5 \mathrm{eq}$ ) of tetra-n-octylammonium bromide in $150 \mathrm{~mL}$ of toluene and add it to the gold solution in the round bottom flask. Stir at maximum speed for 15 minutes until solution is a cloudy dark orange color (see Note 2).

3. While continuing to rapidly stir, cover the round bottom flask with a septum stopper and using a syringe add dropwise $0.7 \mathrm{~mL}$ ( $5 \mathrm{mmol}, 2$ eq) of 1-pentanethiol over the course of 15 minutes. Stir until the solution presents a cloudy deep white color (see Note 3 ).

4. Remove the stopper and quickly add a freshly prepared solution of $2.0 \mathrm{~g}(50 \mathrm{mmol}, 20 \mathrm{eq})$ of sodium borohydride in $10 \mathrm{~mL}$ of Type I ultrapure water. Stir the solution for 5 hours (see Note 4).

\footnotetext{
${ }^{1}$ Weigh the gold salt using a plastic spatula, not a metallic one that can potentially reduce gold salts. Make sure all the gold salt is dissolved.

${ }^{2}$ Stirring is one of the key components of the process. Maintain fast stirring for the rest of the synthesis, using the recommended stir bar.

${ }^{3}$ Do not add more 1-pentanethiol to achieve the white color. Wait a prudent amount of time (20 minutes) and the color should appear, otherwise some of the components are impure and the process should be restarted with new materials.

${ }^{4} \mathrm{~A}$ black color should appear as soon as the sodium borohydride is added. If it takes more than 3 seconds to appear, the process should be started again and the solution discarded as slow appearance of the black color will indicate polydisperse product.
} 
5. Using a separatory funnel, remove the water phase (colorless) from the toluene solution (black). Evaporate the majority of the solvent under reduced pressure at $40{ }^{\circ} \mathrm{C}$ (see Note 5).

6. Add $900 \mathrm{~mL}$ of 200 proof ethanol and mix until the solid is completely dispersed. Store the flask at $-20^{\circ} \mathrm{C}$.

\subsection{Purification of gold nanoparticles}

1. Two days after the synthesis, the nanoparticles precipitate and a black solid is observed at the bottom of the flask. Carefully remove the ethanol solution (brown color) without dispersing the precipitate (see Note 6).

2. Add fresh 200 proof ethanol and mix the solution until the nanoparticles are dispersed. Leave the solution at $-20{ }^{\circ} \mathrm{C}$ until precipitation is complete (see Note 7).

3. Repeat the first and second steps until the ethanol solution is colorless after precipitation (approximately 5 times) (see Note 8).

4. Remove the solvent and redisperse the precipitate in $10 \mathrm{~mL}$ of 200 proof ethanol. Sonicate the solution for 10 minutes.

5. Using a $3.0 \mathrm{~cm}$ grade 1 filter paper circle over a $25 \mathrm{~mm}$ filter holder (No. 5 stopper) attached to a vacuum line, wash the nanoparticles several times with 200 proof ethanol redispersing the precipitate in each wash (see Note 8).

6. Recover the solid from the filter paper.

7. Dissolve the nanoparticles in a minimal amount of toluene and analyze the pentanethiolcapped AuNPs using mass spectrometry (LDI) paying particular attention for the presence of a peak at $466 \mathrm{~m} / \mathrm{z}$ (TOAB). If the peak is present repeat steps 5 and 6 until it is no longer observed (see Notes 9 and ${ }^{\mathbf{1 0}}$ ) (13).

8. Use transmission electron microscopy (TEM) to obtain the average particle diameter and use nuclear magnetic resonance (solvent $-\mathrm{CDCl}_{3}$ ) to confirm purity.

\subsection{Functionalization of gold nanoparticles (from the Murray place exchange) (14)}

1. Dissolve $30 \mathrm{mg}$ of the purified pentanethiol-capped AuNPs in $10 \mathrm{~mL}$ of dry dichloromethane and bubble the solution with nitrogen for 5 minutes.

\footnotetext{
${ }^{5}$ No more than $40{ }^{\circ} \mathrm{C}$ should be used, otherwise nanoparticles will grow larger and polydispersity will be observed.

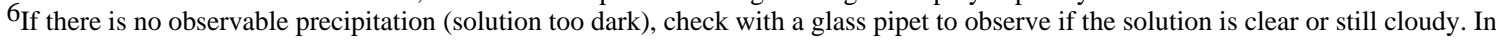
case of a cloudy solution, let sit at $-20^{\circ} \mathrm{C}$ for another day.

${ }^{7}$ No sonication should be used in the first cleanings.

${ }^{8}$ Acetone can be used for faster precipitation/filtration.

${ }^{9}$ If TOAB is still present after several cleanings, pour the solid nanoparticles into a $1000 \mathrm{~mL}$ round bottom flask, add $5 \mathrm{~mL}$ of toluene to dissolve (brownish color appears), and add $900 \mathrm{~mL}$ of ethanol (5). Repeat the process from step 1 (this procedure can be repeated until TOAB is removed).

${ }^{10}$ If TOAB is still present, an alternative procedure for cleaning is the use of acetonitrile. Dissolve the AuNPs in hexanes and extract multiple times with acetonitrile (AuNPs remain in upper hexanes phase and the TOAB transfers to the lower acetonitrile layer). Collect the hexanes phase and evaporate the solvent at reduce pressure $\left(<40^{\circ} \mathrm{C}\right)$.
} 
2. Separately dissolve $150 \mathrm{mg}$ of 23-mercapto-3,6,9,12-tetraoxatricosan-1-ol (or the ligand of interest) in $10 \mathrm{~mL}$ of dichloromethane and bubble with nitrogen for 5 minutes.

3. Mix the two solutions in a $50 \mathrm{~mL}$ round bottom flask, cap with a plastic stopper, and stir (0.5" octagonal magnetic stir bar) for 2 days.

4. Remove the solvent under reduced pressure and redissolve the now functionalized nanoparticles in $10 \mathrm{~mL}$ Type I ultrapure water, obtaining a brownish colored solution.

5. Purify the solution in 10,000 MWCO snakeskin pleated dialysis tubing membrane by dialyzing the system for 5 days using deionized water in a $5000 \mathrm{~mL}$ polypropylene beaker (see Note 11).

6. Recover the AuNP solution from the dialysis bag and lyophilize the nanoparticles. A black solid is obtained.

7. Dissolve a small amount of the solid in $\mathrm{D}_{2} \mathrm{O}$ (for NMR) and the rest in $2 \mathrm{~mL}$ Type I ultrapure water.

8. Calculate the concentration according to the reported extinction coefficient methodology using the size value obtained from TEM (15).

9. Store at $4{ }^{\circ} \mathrm{C}$.

\section{Acknowledgments}

This work was supported by the NIH (GM077173 and EB014277)

\section{References}

1. Faraday M. The Bakerian Lecture: Experimental Relations of Gold (and Other Metals) to Light. Philos Trans R Soc London. 1857; 147:145-181.

2. Saha K, Bajaj A, Duncan B, Rotello VM. Beauty is Skin Deep: A Surface Monolayer Perspective on Nanoparticle Interactions with Cells and Biomacromolecules. Small. 2011; 14:1903-1918. [PubMed: 21671432]

3. Brust M, Walker M, Bethell D, Schiffrin DJ, Whyman R. Synthesis of Thiol derivatised Gold Nanoparticles in a Two-phase Liquid-Liquid System. J Chem Soc Chem Commun. 1994; 7:801802.

4. Li Y, Zaluzhna O, Xu B, Gao Y, Modest JM, Tong YJ. Mechanistic Insights into the Brust-Schffrin Two-Phase Synthesis of Organo-chalcogenate-Protected Metal Nanoparticles. J Am Chem Soc. 2011; 133:2092-2095. [PubMed: 21268580]

5. Cho M-H, Niles A, Huang R, Inglese J, Austin CP, Riss T, Xia M. A Bioluminescent Cytotoxicity Assay for Assessmente of Membrane Integrity Using a Proteolytic Biomarker. Toxicol In Vitro. 2008; 22:1099-1106. [PubMed: 18400464]

6. Waters CA, Mills AJ, Johnson KA, Schiffrin DJ. Purification of dodecanethiol derivatised gold nanoparticles. Chem Commun. 2003:540-541.

\footnotetext{
${ }^{11}$ During the first day water should be changed every two hours, the second and third day every 6 hours, and during the last three days every 12 hours.
} 
7. Murphy CJ, Gole AM, Stone JW, Sisco PN, Alkilany AM, Goldsmith EC, Baxter SC. Gold Nanoparticles in Biology: Beyond Toxicity to Cellular Imaging. Accounts Chem Res. 2008; 41:1721-1730.

8. Zhu Z-J, Tang R, Yeh Y-C, Miranda OR, Rotello VM, Vachet RW. Determination of Intracellular Stability of Gold Nanoparticle Monolayers using Mass Spectrometry. Anal Chem. 2012 doi: $10.1021 / \mathrm{ac} 203408 \mathrm{v}$.

9. Hoffman AS. The origins and evolution of "controlled" drug delivery systems. J Control Release. 2008; 132:153-163. [PubMed: 18817820]

10. Kanaras AG, Kamounah FS, Schaumburg K, Kiely CJ, Brust M. Thioalkylated tetraethylene glycol: a new ligand for water soluble monolayer protected gold clusters. Chem Commun. 2002:2294-2295.

11. Moyano DF, Rotello VM. Nano Meets Biology: Structure and Function at the Nanoparticle Interface. Langmuir. 2011; 27:10376-10385. [PubMed: 21476507]

12. Miranda OR, Chen H-T, You C-C, Mortenson DE, Yang X-C, Bunz UHF, Rotello VM. EnzymeAmplified Array Sensing of Proteins in Solution and in Biofluids. J Am Chem Soc. 2010; 132:5285-5289. [PubMed: 20329726]

13. Yan B, Zhu Z-J, Miranda OR, Chompoosor A, Rotello VM. Laser desorption/ionization mass spectrometry analysis of monolayer-protected gold nanoparticles. Anal Bioanal Chem. 2010; 396:1025-1035. [PubMed: 19911174]

14. Hostetler MJ, Green SJ, Stokes JJ, Murray RW. Monolayers in Three Dimensions: Synthesis and Electrochemistry of $\omega$-Functionalized Alkanethiolate-Stabilized Gold Cluster Compounds. J Am Chem Soc. 1996; 118:4212-4213.

15. Liu X, Atwater M, Wang J, Huo Q. Extinction coefficient of gold nanoparticles with different sizes and different capping ligands. Colloid Surface B. 2007; 58:3-7. 


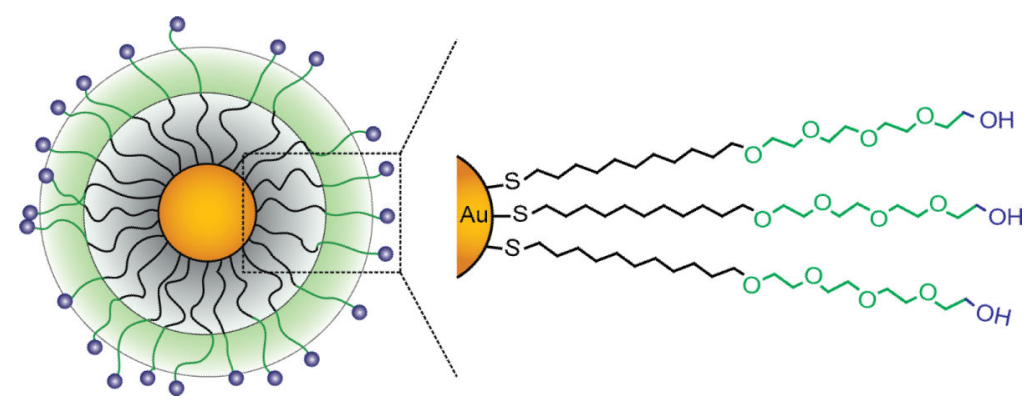

Fig. 1.

Gold nanoparticle chemical structure. The ligand is composed of three parts namely the sulfur atom (binding with gold), alkyl chain (nanoparticle stability) and a tetraethylene glycol spacer (biocompatibility and solubility). 